\title{
Management System Innovation of Promoting the Development of the Internet Era Strategic Transformation of Continuing Education
}

\author{
Luo xindong \\ BeiJing WuZi University, BeiJing, China
}

\begin{abstract}
Based on the status of development of continuing education and future trends, managing innovation system of reform in the succession of continuing education should be based on actual. Especially in the Internet era, but also to innovation and development, we should seriously study the grasp and development trend of continuing education under the new situation, breaking institutional barriers, and vigorously encouraging reform and innovation of management system is the inevitable in the development of education.
\end{abstract}

KEYWORD: Internet; Continuing Education Development; Innovation of Management System

Economic development must be on the premise of improving the national comprehensive quality and continuing education in the Internet age than ever arouses concern of the whole society. Continuing education as one of the core education form of national education series has built its irreplaceable role for the learning society effectively, but continuing education under traditional management systems is facing severe development problems.

\section{INTERNET ERA BACKGROUND OF THE DEVELOPMENT OF CONTINUING EDUCATION}

Internet era implied development opportunities of continuing education. New way of learning brought by industrial structure transfer, without borders career and IT promoted continuing education of university education gradually from the edge toward the center.

\subsection{Industrial Structure Transfer and Personnel Needs}

Internet technology accelerated a series of changes in China's economy and the economic growth mode was different from any other era, so the transformation of the industrial structure birthed the tens of millions of new industry, new career, but also every year millions workers between different industries achieved the transfer [1]. Although these different needs of members of the community in the education learning content and learning methods, but it is without doubt that continuing education will soon play an increasingly important role in our country. Continuing Education is the combination of school education and socio-economic development, which can effectively improve the quality of employees, to provide human resources for the successful transformation of the industry and to provide force for the rapid development of enterprises; while continuing education is the "stabilizer" in the transformation of social development education, owing to re-employment of laid-off workers need continuing education to provide more convenient learning resources to enhance the practitioner's professional competence. Transition adjustment of industrial structure will accelerate the transformation of our country continuing education on teaching content, teaching methods and teaching methods.

\subsection{Borderless Career and Lifelong Learning}

New science, new knowledge, new technology after another, broke the concept of lifelong career in the Internet era. Borderless career subverted people twostage model, which meant "the first half of education, and the second half of busy work", and "never too late to learn" was no longer in the concept level. To make his career not stop, it forces professionals to constantly re-planning, design your own career, and in order to have the opportunity to seek to better career development, it forces us constant re-education and retraining, updating 
knowledge and skills. Lifelong learning is necessary for every member of society in order to adapt to changes of the borderless career and the norm state of uninterrupted continuing education. Continuing education which is the unique characteristics of diverse talent training mode is an effective way of human capital accumulation under the background of borderless career. Developed countries take continuing education as an important means to maintain a competitive advantage. From the improving of our comprehensive national strength, strategic technological competition and talent competition, Our country education focusing on reconstructing a new continuing education management system optimizes the allocation of educational resource so as to establish the needed education system adapted to social development, which creates a situation for social members participating in at any time.

\subsection{New Way of Learning in the Internet Era}

In the internet age, with the widespread popularity of the rapid development of China's IT technology and smart phones, China has the world's largest number of mobile phone users and the number of users of the international IT ranks second in the world. China's Sina Weibo and Tencent Weibo were opened in less than a year and a half to break the 100 million users [2]. Development of information technology not only expands the boundaries of the career, but also profoundly changes people's thinking patterns and communication methods. The rapid development of information technology is changing the traditional education system, education mode, challenging the traditional concept of continuing education, breaking the constraints of time, changing the content and methods of teaching. The process of economic development has proven: In the Internet age, information technology as a carrier of learning way will become the new model of continuing education development. It brings opportunities in the development of continuing education, while also subtly changing the organization and operation mode of continuing education [3].

\section{CHINA'S CONFUSION OF DEVELOPING CONTINUING EDUCATION}

Continuing Education is an important part of completing lifelong learning in our modern national education system, simultaneously it is an important way to achieve knowledge update and expand the technical skills, but compared with developed countries, continuing education development in China is still lagging behind. Especially in the Internet era, it still faces many practical problems to be solved, focusing on the following aspects:

\subsection{Weak Legislative Building}

Continuing education involves all areas and all members of society, the breadth of learners and diversity of school modes has made continuing education become a huge social organization system. Continuing education covered the whole society and all areas will urgently require the government to conduct macro-management of continuing education, mainly representing law regulation and guide. From the successful experience of the world of continuing education, Legislation is an important means of national legislative intervention to manage development. In terms of legislation, although the legislation of continuing education has been started, it is still in its infancy. Although China's Education Law and the Higher Education Act made a lot of regulations on continuing education school, but the relevant provisions relating to continuing education is mostly scattered and there is no China specially continuing education law and no system, supporting the continuing education policy and regulations, and contrary to China burgeoning demand for continuing education.

\subsection{Lack of Quality Control}

Education is an important means of investment in human resources, but the time of continuing education development is still relatively short, so low quality of continuing education is an indisputable fact, a very important reason is that continuing research on monitoring and evaluation of the quality of continuing education is lagging behind. For a long time, our country does not build a complete macroscopic monitoring and evaluation system of continuing education, and no micro-level self-assessment system. The quality of continuing education, benefits cannot be effectively controlled in the field of continuing education, unworthy of even a disguised sale certificate situations have occurred. Therefore, the establishment of a complete and scientific quality monitoring and evaluation system is the necessary link to improve the quality of continuing education and promote the orderly competition and healthy development.

\subsection{Pay not Enough Attention}

Influenced by traditional ideas, the social from all walks of life are biased understanding of continuing education, some colleges and universities did not even take continuing education into the overall plan for the development of school. Whether in teaching management, or in the capital investment, it is the very common phenomenon that we heavy general education and light continuing education. In both local colleges and universities and industry subordinates key institutions, many colleges and universities are not borne by the continuing 
education of teachers included teachers' workload assessment. Moreover, few teachers are willing to take the initiative to study the teaching reform of continuing education and continuing education and jobs education of in-service personnel are hard to become the focus of education in college teaching job. However, the internationally renowned universities, such as Harvard University, the University of Tokyo in Japan, the United Kingdom's University of Cambridge and so invariably rank continuing education, undergraduate and graduate education as the three common part of modern higher education.

\section{PROPOSAL OF IMPROVING CONTINUING EDUCATION MANAGEMENT SYSTEM IN THE INTERNET ERA}

Continuing Education is a compensation opportunity for national basic education, but the law of development of continuing education has its own uniqueness, therefore, based on the characteristics of continuing education, we should reshape the educational philosophy of continuing education and build a new education management system.

\subsection{Accelerate the Construction of Legal System and Clear the Position of Continuing Education}

Continuing education is important to ensure that legislation is the healthy and orderly development, but also an important way to manage and regulate national continuing education. With the rapid development of continuing education needs, drawing on the experience of education powers, developing continuing education regulations is the only way to make continuing education management direction toward legalization. Therefore, enterprises and various non-public economic entities legally independent from the clear responsibility and obligation to continue to carry out educational activities, protection of the rights and obligations of learners to ensure the state of continued education in lifelong education system to create good social environment.

\subsection{Establish an incentive mechanism and an open operating system}

In the internet era, the breadth and diversity of continuing education requirements of the competent department of education must establish the effective incentive mechanism, which is the steady development of the steady development of continuing education. Therefore, the education authorities should strengthen its macro-control functions, using the appropriate operating system open to expand the autonomy of continuing education, fully stimulate the vitality of the school to form orderly competition system of independent schools, government oversight and quality-oriented, highlighting the school characteristics of continuing education coupled with the market. It not only can reduce the pressure which continuing education management bears, but also can fully mobilize the enthusiasm of the main body of running a school.

Continuing education in the Internet age has social and inclusive, so based on the characteristics of continuing education for amateur education, main body of running a school must set up the operational system of open, to truly realize the significance of the open education, namely: open learning objects, open learning environment, open learning form and open learning time.

\subsection{Sound Restraint Mechanisms and Improve the Quality of Continuing Education}

Given the freedom to meet the learning freedom, while continuing to protect the quality of education, it must establish an effective monitoring mechanism. To summarize the previous management experience in full, our country must establish quality evaluation system in line with the concept of lifelong education and improve the effective continuing education evaluation system, to ultimately promote coordination and development. In short, based on the quality certification, the higher continuing education teaching evaluation system should establish and improve learning outcomes and occupational competency assessment system to ensure that higher education system continues to work with the interface between the needs of the job market, giving full play to the role of the quality standard evaluation mechanism in promoting continuing education to improve the quality and stability.

\subsection{Build Brand Characteristics and Education Network Platform}

To build a high level of continuing education based on Information technology, our country should adhere to reasonable layout, different characteristics, management practices principle, and establish continuing education information sharing platform, overall planning and accelerating the construction of the network organization system of continuing education organizations. It includes: the integration of system resources establishing information and management platform of continuing education; the timely promotion of related information and lubrication of information channels building network convergence platform of continuing education; the establishment of credit recognition system on the network platform, which creates conditions for students at the right time, the right place to receive 
education to expand the overall coverage of continuing education.

Education brand is the most competitive in the intangible assets. Our country should build a network platform of Continuing education, but also implement brand strategy to realize own continuing education for sustainable development and the only way to participate in market competition. In pragmatic continuing education services market, continuing education, which increases the intensity of refining school characteristics and preforms brand development strategy of their own continuing education. During the China's key development areas, technical innovation field and professional talent shortage, our country should foster a number of continuing education programs with high quality, good reputation, strong public service and distinctive, to promote rapid industrialization of the process of continuing education market, ultimately forming continuing education industry consistent with Internet age requirements.

\section{CONCLUSION}

Continuing education career occupies an important strategic position in the big powers of human resources. Especially in the Internet era, continuing education will greatly benefit from the development of information technology. IT is not just a technology tool of effectively promoting the information technology of continuing education, and more importantly, it provides opportunities for the development of continuing education because strong demand for professional skills personnel is needed for the development of information technology. To meet new trends of the continuing education, our country must take innovative ideas to consider about the problem of continuing education management system, developing the overall advantages and integrating system resources to make continuing education path depth towards information technology, diversified, individualized.

\section{REFERENCES}

[1] Dongsheng, Sun Xiaoxia. Adult Education Trends of Harmonious Society. China Adult Education, 2009(24): 18. (In Chinese)

[2] Yan Xing, Chang Yaping. Summary of Microblog Research. Intelligence Magazine, 2011(9): 61. (In Chinese)

[3] Zhang Wenzhong, Zong Bojun. Trends and Management System Reform of College Adult Education. Continuing Education Research, 2010 (3): 24. (In Chinese) 